\title{
EXPLORING RECIPROCITY IN PERCEPTIONS ON TELECARE WITHIN THE INFORMAL CARER-CARE RECEIVER DYAD**
}

\begin{abstract}
Informal carers' telecare acceptance decisions depend on how their care recipients perceive telecare, yet this relationship has not been researched very much. This article draws on qualitative data gathered from informal carers to explore reciprocity in telecare perceptions within dyads of informal carers and care receivers. A 4-month intervention study was conducted from 2018 to 2019 in the Central Slovenia region. A purposive sample of 22 older adults and their informal carers tested two telecare solutions. Thematic analysis was conducted using Atlas.ti 8, with four themes emerging: 1. the benefits of telecare use for older adults; 2. reluctance, rejection or negative perceptions of telecare; 3. the potential violation of older adults' privacy; and 4. the importance of external and internal information for effective telecare use. This study confirms that that telecare perception is dyadically interdependent.

Keywords: assistive technologies, informal care, ageing in place, dyads, older adults
\end{abstract}

\section{Introduction and theoretical background}

Recently, ageing in place, which enables older adults to remain at home in their communities for as long as possible and avoid institutional care, has become the dominant paradigm for successful ageing (Normie, 2011). However, in most European Union countries, this paradigm has been

* Simona Hvalič-Touzery, PhD, Teaching Assistant, Faculty of Social Sciences, University of Ljubljana, Slovenia; Kaja Smole-Orehek, Teaching Assistant, Faculty of Social Sciences, University of Ljubljana, Slovenia; Vesna Dolničar, PhD, Associate Professor, Faculty of Social Sciences, University of Ljubljana, Slovenia.

** The authors acknowledge that the projects [Smart ICT Solutions for Active and Healthy Ageing. Integrating Informal eCare Services in Slovenia, ID L5-7626; Factors impacting [the] intention to use smart technology-enabled care services among family carers of older people in the context of long-distance care, ID J5-1785; Understanding and analysis of users' needs for the development of e-services for integrated social and health care in the ageing society, ID L5-9337; Programme Internet research, P5-0399] were financially supported by the Slovenian Research Agency.

DOI: $10.51936 /$ tip. $58.3 .840-859$ 
insufficiently supported by social policies. Trends such as the lack of access to formal long-term care services, the poor quality and high cost of longterm care services, and the shortfall in adequately trained health and social service providers regarding ageing issues have created unmet care needs and care poverty (Kröger et al., 2019; Spasova et al., 2018). Although longterm care systems differ in individual European countries, the challenge and complexity of providing increased care needs is shared by all (Šadl and Hlebec, 2018; Spasova et al., 2018). Informal care accounts for the majority of care hours in all European countries, even those with large and officially supported sectors that provide care to older adults. Therefore, there is considerable and increasing pressure on informal carers (Eurocarers, 2018; Spasova et al., 2018; World Health Organization Regional Office for Europe, 2012). While society expects informal carers to continue to provide care, existing support measures only partially address informal carers' needs. Telecare solutions hold the potential of addressing some of their challenges (Eurocarers, 2019), as increasingly recognised in European policymaking (Eurocarers, 2018, 2019; European Ageing Network, 2019; European Commission, 2021). Telecare solutions can be used to serve two interlinked purposes: to improve the independence and well-being of care recipients, and to support informal carers through improved well-being and reduced care burdens (Topo, 2009). According to Hassan (2020), despite the growing interest in potential telecare solutions offered for informal care, diverse and overlapping questions concerning their deployment remain unanswered. He proposed several recommendations to influence how telecare is accepted by older adults and their carers and to challenge academic researchers to establish important evidence to guide the design of telecare solutions. While many researchers have focused on older adults' acceptance of telecare (Jaschinski et al., 2021; Liu et al., 2016; Peek, 2017; Tsertsidis et al., 2019) and the outcomes of its use, many researchers do not have a full understanding of informal carers' acceptance of telecare solutions (Cook et al., 2018; Dolničar et al., 2017; Guisado-Fernández et al., 2019) and the outcomes of telecare use for informal carers (Andersson et al., 2017; Harward, 2016; Smole-Orehek et al., 2019).

Our study was guided by the findings of a scoping study conducted by Hvalič Touzery et al. (2021), which revealed informal carers' views on the benefits of telecare use in caring for older people and showed that older people's concerns and attitudes to telecare significantly influence how they accept telecare. Among the 37 empirical studies included in the analysis, 21 indicated that informal carers' technology-acceptance decisions depended on care recipients' perceptions, experiences, attitudes and desires regarding telecare systems (e.g. Cook et al., 2018; Jaschinski and Ben Allouch, 2019; Guisado-Fernández et al., 2019; Verloo et al., 2020). For example, a 
study conducted among Dutch informal carers found that while informal carers strongly influence care-related decisions, the majority of participants stressed that actual use of telecare depends greatly on the care recipient's wishes and that they would not use it without the care recipient's consent (Jaschinski and Ben Allouch, 2019). However, carers, especially informal ones, influence older adults' intention to use telecare (Jaschinski et al., 2021; Luijkx et al., 2015).

The overall aim of the study was to investigate reciprocity in informal carers' and care recipients' perceptions of telecare since this is one of the factors that influences informal carers' acceptance of telecare solutions. The reciprocity of telecare perception refers to what is mutually understood by way of benefits, concerns, attitudes, experiences, feelings and wishes concerning telecare usage within the informal carer-care receiver dyad. Older adults' views on telecare were captured by informal carers either directly (with quotes from older people) or indirectly (by reporting on older adults' feelings and experiences). Two research questions are to considered here: (1) Which differences exist in perceptions and decision-making processes regarding telecare use within the informal carer-care recipient dyad; and (2) Which factors shape perceptions and decision-making processes regard-

842 ing telecare use within the informal carer-care recipient dyad?

The remainder of the article is structured as follows. Section 2 describes the procedures and methods used in the empirical part of the study. Section 3 presents the empirical results of the thematic analysis, while section 4 discusses the empirical findings. Section 5 presents a discussion of the empirical findings and describes the study's limitations. Finally, section 6 offers future research directions and conclusions.

\section{Methodology}

\section{Study Design and Procedure}

We conducted a 4-month intervention study using a qualitative research design (Lobo et al., 2017). This approach was chosen because it is specifically tailored to evaluating the direct effects of certain preventive interventions (Thiese, 2014), which is consistent with the nature of this study. The intervention was performed between 2018 and 2019 in the Central Slovenia region. A total of 26 dyads, each including an older care receiver and their primary informal carer, were recruited. To meet the aim of the study, we conducted surveys and interviews with working informal carers only. Basic social, health, care provision and demographic data were collected via the survey at the start of the intervention. Subsequently, two semi-structured interviews were conducted with each informal carer during the first and 
fourth months, each lasting around 1 hour. The informal carers were asked about their caring situations, experiences with new technology, use of the tested telecare services, and the psychological outcomes of telecare. These in-depth interviews were audio-recorded and fully transcribed. Personal information was anonymised. We provided all participants with gift certificates to show appreciation for their time. The study was approved by the Slovenian Committee for Medical Ethics (0120-193/2018/15).

\section{Apparatus}

Older care receivers had one of the two sets of the tested telecare equipment installed in their homes, while their informal carers used relevant telecare mobile apps to monitor certain activities in each older person's home and to receive push notifications. All of an older person's information collection, communications and responses happened without manual actions (e.g. using environmental sensors like motion and door sensors, smoke detectors, and fall detectors). Sensors and fall detectors were set to generate alerts when they detected data patterns which deviated from preestablished thresholds. Only the use of emergency pendants anticipated the active role of the older people, who needed to press the alarm in the case of an emergency. The second service was used by 7 out of 22 dyads, alongside the environmental sensors and an emergency pendant that offered access to a $24 / 7$ call centre and included a fall-detection feature with automatic detection of a user's fall. The participants were not charged for the use of this equipment or services.

\section{Participants}

Due to the restrictive eligibility criteria, purposive sampling was used to identify and select care receivers and their informal carers. The eligibility criteria for care receivers were that they should be: (i) interested in participating in our study; (ii) 65 years of age or older; (iii) need help with daily living activities; and (iv) live alone in their own households. Informal carers' eligibility criteria were that they should be: (i) a primary carer; (ii) a family member of an older person; (iii) a provider of long-term care (LTC) to an older person; (iv) an owner of a smartphone; and (v) interested in participating in our study. Of the 26 dyads of care receivers and carers, 22 completed the study. 
Table 1: BASIC INFORMATION ON THE DYADS

\begin{tabular}{|c|c|c|c|c|c|}
\hline Dyad & $\begin{array}{l}\text { Older } \\
\text { person's } \\
\text { age } \\
\text { group } \\
\end{array}$ & $\begin{array}{l}\text { Informal carer's } \\
\text { relationship } \\
\text { to the older } \\
\text { person } \\
\end{array}$ & $\begin{array}{l}\text { Spatial distance } \\
\text { from informal } \\
\text { carer }\end{array}$ & $\begin{array}{l}\text { Older person's } \\
\text { dependency }\end{array}$ & $\begin{array}{l}\text { Frequency of } \\
\text { informal carer's } \\
\text { visits }\end{array}$ \\
\hline Dyad 1 & $70-79$ & Daughter & 10-min. drive & $\begin{array}{l}\text { Moderately } \\
\text { dependent }\end{array}$ & $\begin{array}{l}\text { At least once } \\
\text { a week }\end{array}$ \\
\hline Dyad 2 & $70-79$ & Daughter-in-law & $\begin{array}{l}\text { Within walking } \\
\text { distance }\end{array}$ & $\begin{array}{l}\text { Moderately } \\
\text { dependent }\end{array}$ & $\begin{array}{l}\text { At least once } \\
\text { a month } \\
\end{array}$ \\
\hline Dyad 3 & $80-89$ & Son & 30-min. drive & $\begin{array}{l}\text { Slightly } \\
\text { dependent }\end{array}$ & $\begin{array}{l}\text { At least once } \\
\text { a week }\end{array}$ \\
\hline Dyad 4 & $80-89$ & Daughter & 30-min. drive & $\begin{array}{l}\text { Moderately } \\
\text { dependent }\end{array}$ & $\begin{array}{l}\text { Several times } \\
\text { a week }\end{array}$ \\
\hline Dyad 5 & $80-89$ & Son & 30-min. drive & $\begin{array}{l}\text { Moderately } \\
\text { dependent }\end{array}$ & $\begin{array}{l}\text { Several times } \\
\text { a week }\end{array}$ \\
\hline Dyad 6 & $70-79$ & Son & 30-min. drive & $\begin{array}{l}\text { Severely } \\
\text { dependent }\end{array}$ & $\begin{array}{l}\text { Almost every } \\
\text { day }\end{array}$ \\
\hline Dyad 7 & $\begin{array}{l}90 \text { or } \\
\text { older }\end{array}$ & Daughter & 30-min. drive & $\begin{array}{l}\text { Moderately } \\
\text { dependent }\end{array}$ & $\begin{array}{l}\text { Several times } \\
\text { a week }\end{array}$ \\
\hline Dyad 8 & $70-79$ & Daughter & 30-min. drive & $\begin{array}{l}\text { Severely } \\
\text { dependent }\end{array}$ & Every day \\
\hline Dyad 9 & $\begin{array}{l}90 \text { or } \\
\text { older }\end{array}$ & Son & $\begin{array}{l}\text { Within walking } \\
\text { distance }\end{array}$ & $\begin{array}{l}\text { Moderately } \\
\text { dependent }\end{array}$ & $\begin{array}{l}\text { Several times } \\
\text { a week }\end{array}$ \\
\hline Dyad 10 & $80-89$ & Son & 30-min. drive & $\begin{array}{l}\text { Moderately } \\
\text { dependent }\end{array}$ & $\begin{array}{l}\text { At least once } \\
\text { a week }\end{array}$ \\
\hline Dyad 11 & $\begin{array}{l}90 \text { or } \\
\text { older }\end{array}$ & Daughter & 30-min. drive & $\begin{array}{l}\text { Slightly } \\
\text { dependent }\end{array}$ & Every day \\
\hline Dyad 12 & $80-89$ & Daughter & 10-min. drive & $\begin{array}{l}\text { Severely } \\
\text { dependent }\end{array}$ & Every day \\
\hline Dyad 13 & $80-89$ & Daughter-in-law & 10-min. drive & $\begin{array}{l}\text { Slightly } \\
\text { dependent }\end{array}$ & $\begin{array}{l}\text { At least once } \\
\text { a week }\end{array}$ \\
\hline Dyad 14 & $80-89$ & Daughter & 30-min. drive & $\begin{array}{l}\text { Severely } \\
\text { dependent }\end{array}$ & $\begin{array}{l}\text { Several times } \\
\text { a week }\end{array}$ \\
\hline Dyad 15 & $80-89$ & Daughter & 30-min. drive & $\begin{array}{l}\text { Slightly } \\
\text { dependent }\end{array}$ & $\begin{array}{l}\text { At least once } \\
\text { a week }\end{array}$ \\
\hline Dyad 16 & $80-89$ & Son & 1-hour drive & $\begin{array}{l}\text { Slightly } \\
\text { dependent }\end{array}$ & $\begin{array}{l}\text { At least once } \\
\text { a week } \\
\end{array}$ \\
\hline Dyad 17 & $80-89$ & Son & 10-min. drive & $\begin{array}{l}\text { Moderately } \\
\text { dependent }\end{array}$ & Every day \\
\hline Dyad 18 & $80-89$ & Son & $\begin{array}{l}\text { Thirty-minute } \\
\text { drive }\end{array}$ & $\begin{array}{l}\text { Slightly } \\
\text { dependent }\end{array}$ & $\begin{array}{l}\text { At least once } \\
\text { a month } \\
\end{array}$ \\
\hline Dyad 19 & $80-89$ & Daughter & 10-min. drive & $\begin{array}{l}\text { Slightly } \\
\text { dependent }\end{array}$ & $\begin{array}{l}\text { Almost every } \\
\text { day }\end{array}$ \\
\hline Dyad 20 & $80-89$ & Daughter & 30-min. drive & $\begin{array}{l}\text { Severely } \\
\text { dependent }\end{array}$ & Every day \\
\hline Dyad 21 & $\begin{array}{l}90 \text { or } \\
\text { older }\end{array}$ & Son & 30-min. drive & $\begin{array}{l}\text { Slightly } \\
\text { dependent }\end{array}$ & $\begin{array}{l}\text { At least once } \\
\text { a week }\end{array}$ \\
\hline Dyad 22 & $70-79$ & Daughter & 30-min. drive & $\begin{array}{l}\text { Slightly } \\
\text { dependent }\end{array}$ & $\begin{array}{l}\text { At least once } \\
\text { a week }\end{array}$ \\
\hline
\end{tabular}

Source: Own analysis. 
On average, the care receivers were 83 years old $(\mathrm{SD}=6.04)$, ranging from 73 to 92 years. All but 2 were female, and all but 1 had fallen in the last 5 years; 14 had then required medical assistance. Half of them needed urgent medical help more than once over the last 5 years. Five of them were severely dependent (e.g. unable to independently carry out most daily activities). Eight were moderately dependent (e.g. able to carry out some basic daily activities but needed help with others) while nine were slightly dependent (e.g. able to carry out most daily living activities but required help with certain instrumental activities). Seventeen of them were widowed. Only two older people lived within walking distance of their carers; six of them lived a 10-minute drive away from their carers, and 14 within a 30-minute drive from their carers (Appendix). Most carers were female $(n=13)$ and the majority were the children of the care recipients $(n=20)$. The carers provided the care receivers with 8.5 hours of care per week $(\mathrm{SD}=12.15)$ and had been doing so for an average of 5.9 years $(S D=5.87)$. The carers ranged in age from 35 to 67 years $(M=53.9, S D=7.56)$ and were all employed full time.

\section{Analysis}

A descriptive analysis was conducted of the qualitative data, which included 755 pages of transcribed interview records. The qualitative data were subjected to thematic analysis using Atlas.ti 8 software. Structural coding was also used. This type of coding is question-based and "acts as a labelling and indexing device, allowing researchers to quickly access data likely to be relevant to a particular analysis from [a] larger data set" (Namey et al., 2008: 141; Saldaña, 2011: 84). We coded and analysed the informal carers' quotes which either directly (e.g. carers quoted what the older people had said) or indirectly (e.g. carers described in their own words how the older people had been feeling or acting) addressed the older adults' perceptions of tested telecare solutions. Deductive and inductive approaches were combined during the data coding and analysis. We first drew and concluded from established evidence, but since that evidence was limited, we also included an inductive approach, drawing conclusions from what is in the data (Braun and Clarke, 2012; Saldaña, 2013). A combination of both approaches is often used in qualitative studies (Braun and Clarke, 2012).

\section{Results}

The interviews with the older adults' informal carers provided insights into their care recipients' views on telecare, as well as the informal carers themselves. Four main themes emerged: 1 . the benefits of telecare use for 
older adults; 2. reluctance, rejection and negative perceptions of telecare; 3 . the potential violation of older adults' privacy; and 4. the importance of external and internal information for effective telecare use.

\section{Benefits of Telecare Use for Older Adults}

The informal carers were able to identify several benefits of telecare for those they were caring for, such as enhanced feelings of safety, self-efficacy, improved quality of life, peace of mind, and reassurance. Several carers noted that their care recipients had felt safer once the telecare had been installed. As one carer noted,

Yes, she uses the watch all the time and says to me look, this is my connection to the world in case something happens'. (Carer 15)

One carer mentioned that her severely dependent mother felt more confident and more independent due to the safety net telecare provides. Before using telecare, her mother was unable to carry out most daily activities without help, such as getting up, going to the toilet etc. As this carer put it, her

846 mother needed help with every activity apart from feeding herself. During the first interview, the carer explained that, based on her past experiences with falls, there is an $80 \%$ chance that this care recipient will fall if she tries to get up and walk on her own. Since the installation of telecare, this care recipient has gained the confidence to do some activities on her own, such as going to the toilet and going to the kitchen to eat something while she is home alone. The carer explained this in the following manner:

She was encouraged and went alone, and when she happily made it to the kitchen by herself without falling, I had to applaud that. I also told her that if she didn't have a button around her neck when she did that, that wasn't okay. That she was risking a lot. And the next time she made it to the kitchen on her own, she had the button around her neck. Maybe the fact that she's daring, that she's still showing some independence and that she's alert enough [means] that she's safer with it than without it. I think that's a positive thing. It encourages her to be a bit more independent because she dares to do things on her own and has more confidence. But that's also a placebo effect of technology. (Carer 8)

In this case, telecare had improved the quality of life of the person being cared for, as well as her feelings of self-efficacy.

The benefits for the older adults are also reflected in the informal carers' self-perceived benefits of this technology. Many of them frequently 
mentioned the mutual sense of security the technology provided. One working carer said:

Yes, it's great because, as I said, I'm not always available on the phone during work, and she also knows that I'm hard to reach during work. So, thanks to this device, I worry less, and she also feels safer. (Carer 13)

The benefits for older people of using telecare are seen in the acceptance of telecare solutions by carers. One carer noted,

It doesn't matter how this technology benefits me or my brother, it matters what kind of service my mother gets and what kind of help she gets when something unexpected happens. That's what matters. (Carer 18)

\section{Reluctance, Rejection or Negative Perceptions of Telecare}

Some informal carers noted that, initially, the person they were caring for had expressed some concerns about telecare, such as potentially harmful consequences of its use or it becoming a bother. For some older adults, these fears and concerns were dispelled after they started to use the technology and obtained better explanations on how telecare functions. There was, however, one person who lost interest in telecare after she had started using it and had become more familiar with it. According to her informal carer, she did not see it as suitable for her needs. One older adult who is struggling with several diseases, including breast cancer, was concerned about radiation potentially coming from the emergency pendant that she was wearing around her neck. She consulted her general practitioner about this:

She was afraid of the health consequences of telecare use. Then her doctor reassured her and said that it was not the case. Now it is okay for her to use it... (Carer 14)

Several informal carers mentioned their care recipients' reluctance to rely on telecare. They believed that their care recipients were either concerned about telecare's reliability, did not fully understand how the telecare system works or were worried about the potential health-threatening consequences of telecare use. As these informal carers noted, these reluctant older adults had inappropriately used the telecare technology. This inappropriate use could include an older person not wearing their emergency pendant (which mostly happened where older people were reluctant to use the technology) or an older person triggering their device by mistake or 
because they seeking social interaction. One informal carer reported:

I think she resigned herself to using it, saying, 'I have it here beside me, on the palm of my hand', but she never wore it. (Carer 2)

A few informal carers described how the people they were caring for had mentioned certain negative consequences of telecare use. Some carers gave examples like disputes between older adults and carers over the importance of wearing the emergency pendant, the reduced phone contact with carers, anxiety over being under constant watch and feelings that the pendant was stigmatising and bothersome to wear. A few of these older adults had stopped using their pendants. Several older adults remarked on the light flashes coming from the sensors, especially in their bedrooms at night. One older adult whose mobility is limited and had fallen several times in the past had decided not to use the emergency pendant anymore, although her carer had explained its purpose and importance to her. She did not see its benefits and was also bothered by the light emitted from the sensors:

The watch kept falling out of her hand. It bothered her when she slept. She asked why the sensor light was flashing, why it was red, why this, why that. It really drove me crazy. Then she said she did not want to wear it anymore, that it was useless. (Carer 5)

Since this older adult had refused to use telecare, despite her initial interest in using it, the informal carer also gave up on the solution, even though it interested him:

On the whole, I would be in favour of the whole thing, if it is needed, still being in use. But it seems that my mother is not in favour of it. It bothered her so much, especially one button on the neck. So, she said she didn't want to wear it anymore. I asked why not, but she just said she didn't want it. Well, ok, then she won't wear it anymore. (Carer 5)

Two older adults believed the emergency pendant appeared to reinforce the stereotype about old-age vulnerability. One older person avoided using it. One carer thought the reason for this lay in the fear that the pendant would signal her old age and vulnerability to others. Since this older person did not wish to be perceived in this way, she avoided using other help aids outside her home: 
She only has it beside her bed. I saw it there the last time I visited her. I think she is embarrassed to wear it. (Carer 22)

The older adults' negative views on telecare or its rejection also influenced the informal carers' interest and ability to use telecare, as several informal carers expressed. As one carer whose mother had rejected telecare stated:

Since she won't wear that necklace, I think it's pointless to have it since it doesn't add much functionality and it's the same as having a mobile phone. Since she has not accepted this button, there is nothing I can do. (Carer 2)

\section{The Potential Violation of Older Adults' Privacy}

Most informal carers mentioned that their care recipients had not experienced any privacy concerns with telecare use. They attributed this attitude to a variety of reasons: the care recipient's personality traits, the increased benefits offered by use of the technology, the non-invasive/non-intrusive nature of the devices, each older person's perceived need for telecare, and their attitudes to new technology.

One informal carer whose mother wished to participate in the study mentioned that, even though monitoring could be perceived as an intrusion into an older person's privacy, his mother does not view monitoring in this way:

She doesn't understand it like that, so she doesn't find it problematic, first of all, because she voluntarily decided to participate and, secondly, she doesn't register the sensors anymore; she doesn't mind it, [and] she doesn't see a problem, so I don't find it problematic either. (Carer 21)

In addition, he mentioned that his mother had expressed a great interest in telecare and was impressed by all that it enables:

She thinks it's interesting: 'Wow, that is really crazy what technology makes possible today'. She does not see it as, 'Why are you controlling me now?'. She says, 'That is good, so you saw me go out earlier? Wow'. That is how she perceives it. (Carer 21)

Several carers mentioned privacy concerning the safety and security of their care recipients. Their care recipients view telecare as a solution that 
enables them to live safely in their own homes, and thus the loss of privacy was not an issue for them. Some did not even perceive monitoring as a violation of their privacy:

And I think she's used to them being there now, like a painting you see every day, so she doesn't see them as something that controls her. She knows she can push a button if something's wrong, and that gives her a sense of security. (Carer 19)

Some of the dyads that were not worried about privacy concerns approached the monitoring feature with humour. As one carer vividly described:

We sometimes joke about it. The other day I [asked] her why she did not close the balcony door; it's been open for 15 minutes. She said it was sunny and beautiful and asked if I could see that too. I said, 'Of course I see it'. So, yeah, she's more peaceful, and I am more peaceful. (Carer 4)

A few of the informal carers mentioned that their care recipients had felt like they were being watched. These care recipients expressed they felt their privacy had been violated when the informal carers did not communicate tactfully about the information they had obtained from the environmental sensors or when the care recipients did not completely understand how the telecare system works:

I called her and said to her, 'So, you are still asleep or what? I see it, you know'. And she answered, 'There, now you see where I am; that is not good. I do not like it'. (Carer 3)

Still, the care recipients' privacy concerns did not necessarily reflect their future telecare use or the carer's acceptance. In one dyad, the carer made the decisions, and acceptance was more likely to reflect the older personcarer relationship and his sense of obligation to care for his mother:

Well, I told her that this technology was needed. Right now, it's not that bad, but in the future, it will be, and I will take this technology. Especially if her health will deteriorate. So, I don't care what she thinks. You just have to accept it. Although it is an invasion of her privacy, I feel responsible for her. So, it's better to know as soon as possible if something bad happens because you can't always control how she is. (Carer 3) 
One informal carer whose mother has mild dementia expressed that it is difficult to comment on her mother's feelings regarding telecare and her feelings of safety. However, she did observe her mother's positive reaction to the monitoring feature:

You know, she doesn't even think about it... My mother has a little, she has a little dementia. When I say to her at night that I see where she is, she thinks that's cool. But for her to think about it and have a sense of security... It's hard for me to tell. Maybe. But we haven't talked about it. (Carer 10)

\section{The Importance of External and Internal Information for Effective Telecare Use}

The care recipients had obtained external telecare information from their informal carers, technical support or the initial information when they were approached to participate in this study. The external telecare information the informal carers provided was at the forefront of this analysis because the carers mostly commented on this aspect of the external information. The majority of carers had provided the care recipients with information on how to effectively use the telecare solutions, although their involvement and the tasks they undertook varied. Some carers had helped with some basic maintenance that enabled the care recipients to use the telecare equipment (e.g. calling technical support). Moreover, the informal carers had to explain to the care recipients the importance of wearing the emergency pendant and/or fall detector. One carer explained that she would like to help her mother live as independently as possible, so she encourages her to do the errands she is still capable of doing. Due to her mother's previous experiences with falls, the carer bought her a phone, which her mother put in a drawer; her mother did the same with the emergency pendant. The emergency pendant bothered the carer's mother, so the carer exchanged it for the alarm pendant, which can be worn as a watch. Today, her mother uses it properly:

Now we gave her the phone with the red button. But the problem was she didn't wear it/... But she wears a watch all the time, so at least she can press there. (Carer 15)

According to several informal carers, their care recipients sometimes did not understand that having an emergency pendant on a nearby table would not help much in the case of a fall. The pendant would still be too far 
away to reach should they encounter an emergency, leading several carers to stress the importance of wearing it:

It happened when she was alone that she had the pendant on the table. She left it there and went into another room. I explained that it was not okay because, if something happened, she could not inform anyone about it. Then she understood how important it was to wear it. (Carer 8)

The informal carers spoke with their care recipients about the information they had obtained from the sensor-based monitoring system in various ways. Some carers approached the older adults very tactfully with sensitive information they had obtained about their daily habits. One carer explained,

You see, I'm absolutely setting myself up for this because I'm not even mentioning this to her. That means we could have a psychological drama if I said to her, 'Mum, where were you today? You went to the bathroom six times. Why?'. That would be too much. (Carer 6)

On the other hand, a lack of empathy shown towards the care recipients' feelings regarding telecare services was also observed in the study. One older adult who depended on her carer's help felt beholden to his viewpoint:

She's a bit nervous, moody sometimes. She does not like me controlling her... This control bothers her the most, but she has accepted it because I ignore her comments. I have said that she will use it, and so it will be. (Carer 3)

Internal information, which is based on the older adults' personal experiences from earlier on in their lives, was particularly strong for one older adult, which led to her distrust and rejection of such technology. This older adult frequently mentioned one prior event in which similar technology was proven ineffective:

My mother still thinks about an event that took place about 20 years ago. Her neighbour had an SOS button. She had it when she fell at the front door. Supposedly, she pressed it, and she still died because no one came for some time before they found her... So, we heard that story a lot. That this lady with the button around her neck died. I do not think my mother has the emergency pendant on her. (Carer 22) 
The outcome was that this older adult did not use the telecare service properly, nor did her informal carer. The carer said that, even if her mother fell, she would not make it to the emergency pendant, and even if she did, the carer would not hear her because she does not use her phone at night:

Even if she made it to the button, she'd have to wait until morning for me to see it. I put my phone on silent at night, so I don't hear the phone alarm. (Carer 22)

\section{Discussion}

This article aimed to explore the reciprocity in informal carers' and care recipients' perceptions of telecare. We were interested in exploring older care recipient-carer relationships with respect to the use of telecare, the differences or similarities in their views on telecare and the carers' roles as providers of external information on telecare.

With the main aim of this study in mind, the findings indicate four main themes concerning perceptions of telecare by dyads of informal carers and their care recipients: the benefits of telecare use for older adults; reluctance, rejection and negative perceptions of telecare; the potential violation of older adults' privacy; and the importance of external and internal information for effective telecare use.

In addressing the first research question, this study provided evidence of the agreement between the older care recipients and their informal carers in several dyads regarding the benefits of telecare use. In these cases, the care recipient and the informal carer perceived the monitoring as non-intrusive and as a solution to allow the older adult to live safely in their home; therefore, they believed that telecare would provide sufficient benefits that would outweigh any privacy concerns. However, some evidence in support of the findings of Epstein et al. (2016) was found: there is some contention between older adults (i.e. feeling controlled and stigmatised or fearing possibly harmful consequences related to telecare use) and informal carers (i.e. being informed and in control of the situation when absent) regarding the monitoring system. Further, some informal carers reported disputes with their care recipients due to their inappropriate use of the telecare system. One clear example of such a misunderstanding concerns an older adult who had a pendant alarm nearby while the carer was trying to explain how important it was to wear it. The contradictions between the feelings held by the older adults and the informal carers frequently led to incorrect or only partial use of the telecare system and the lack of willingness to use telecare solutions after the end of the test phase. 
As concerns the second research question, it is now possible to state that the decision-making process about the use of telecare solutions reflects longterm family dynamics and the informal carer-care recipient relationship in a dyad. For example, dyads that had close ties were less concerned about privacy, and other dyads used humour to discuss the monitoring feature of the telecare system. Similar findings were reported by Huber et al. (2013: 452), who found that "the perception of playfulness, as opposed to intrusiveness, was possible only because of the close existing bond between the older adults and their informal carers". When an informal carer held more power in a dyad, their decisions about the use of telecare were one-dimensional and did not coincide with the older person's wishes. Therefore, like Conner and Chase (2015: 457), one may conclude that "caregiving and decision-making are dynamic processes with great diversity" that should also be considered while studying telecare use.

When studying factors that shape perceptions and decision-making processes regarding telecare use within dyads, according to the informal carers' observations we may also conclude that older adults are more positive about telecare solutions when these technologies meet their needs and give them a sense of self-efficacy (Golant, 2017; Jaschinski et al., 2021). In addi854 tion, they were persuaded by their previous experiences and their external sources of information (Golant, 2017), which chiefly comprised informal carers in the case of this study. These influencing factors are also highlighted in this study since the informal carers paid particular attention to the older adults' self-efficacy and independence arising from telecare use and the benefits or potential harm of using the telecare system. They also acted as the main providers of external information about the telecare solution, especially its proper use and basic maintenance. Yet, we observed that the involvement of informal carers and the responsibilities they took on in the telecare use process varied considerably, a finding also reported by Steils et al. (2021). This study, therefore, also demonstrates the importance of involving family members while implementing technology in the lives of older adults, as also reported in previous studies (Jaschinski et al., 2021; Luijkx et al., 2015).

Finally, this study confirms that informal carers' perceptions and acceptance of telecare are intertwined with their care recipients' perceptions of technology since their technology acceptance decisions depended significantly on them. These findings are supported by other researchers (Cook et al., 2017; Dolničar et al., 2017; Epstein et al., 2016; Gibson et al., 2019; Jaschinski and Ben Allouch, 2019; Mitchell et al., 2020; Sriram et al., 2019; Verloo et al., 2020; Williamson et al., 2017) who found that positive perceptions of telecare solutions such as benefits for older people (e.g. independence, connection, and a sense of security) lead to informal carers' 
acceptance of telecare solutions. Still, the results of this study demonstrate that the barrier between the acceptance of telecare solutions and informal carers is often the negative perceptions held by the care recipients or the carers themselves, as also reported in other studies (Dolničar et al., 2017; Guisado-Fernández et al., 2019; Jaschinski and Ben Allouch, 2019; Mitchell et al., 2020; Sriram et al., 2019; Verloo et al., 2020). These negative perceptions were principally the result of the older people's negative experiences with telecare solutions (e.g. loss of independence or pride, violation of privacy, intrusiveness of the solution) or general rejection of telecare solutions (e.g. due to telecare's sudden introduction into their lives, the unreliability of the solution, the care recipients' resistance to change, the feeling that they do not need support, inexperience, and the perception that the solution does not meet their needs).

This study examined under-researched aspects of telecare use concerning the informal care of older adults. The methodology used the provided insights into the informal carers' experiences with telecare, as well as their care recipients' perceptions of it. However, this study has some limitations. The first is the duration of the intervention. When conducting an intervention study to detect and monitor a potentially harmful event, an intervention of longer duration is usually advisable, but we were limited in time and resources. Further, the occurrence of a harmful or unexpected event during the testing phase in this study was low (only five participants experienced an unexpected, potentially harmful event and the device successfully intervened - emergency pendant, smoke detection), meaning that many participants had no real experience with the support and protocols for using telecare. Moreover, one of the telecare services tested was still in the testing phase during the intervention study, leading to several false alarms, especially at the beginning of the study.

\section{Conclusion}

Despite the important role held by family members (often informal carers) in both the decision-making process to use telecare and during the actual use of telecare, little attention has been paid to this aspect of telecare in studies. An earlier scoping study (Hvalič Touzery et al., 2021) reviewed 21 empirical studies that (among other findings) indicated the importance of the influence of either informal carers or care recipients on technology acceptance decisions. However, none of these studies focused exclusively on the views held by both users of telecare. On the contrary, 20 studies were identified that separately focus on the general opinions and perceptions of the carers or care recipients and overlook the dynamics within the informal carer-care recipient dyad that influence telecare use decisions, adoption 
and willingness to use, as also found in our study. One study (Huber et al., 2013) focuses on telecare's impact on the older person-carer relationship, but the dynamics within the dyad were not further explored from the perspective of decision-making processes about telecare. The findings of the present study provide insights into the reciprocity in how telecare is viewed within the dyad, concentrating on differences in the perceptions and decision-making processes concerning telecare use within dyads, and on the factors shaping these perceptions and decision-making processes about telecare use within dyads. The results show there is reciprocity in both the decision-making and perceptions of telecare, which should be considered while exploring telecare's acceptance factors among older adults and informal carers. This reciprocity in views on telecare combined with other acceptance factors, like family dynamics and the informal carer-care recipient relationship in a dyad, as well as decision-making processes within dyads regarding telecare use, warrants further empirical and conceptual research. Still, the findings of this study can be used to inform researchers, policymakers, telecare providers and developers, and health and social care professionals to better understand the importance of family involvement in implementing technology in the lives of older adults and to guide future planning for telecare deployment within the long-term care system.

\section{BIBLIOGRAPHY}

Andersson, Stefan, Christen Erlingsson, Lennart Magnusson and Elizabeth Hanson (2017): Information and Communication Technology-Mediated Support for Working Carers of Older Family Members: An Integrative Literature Review. International Journal of Care and Caring 1 (2): 247-273.

Braun, Virginia and Victoria Clarke (2012): Thematic Analysis. In H. Cooper, P. M. Camic, D. L. Long, A. T. Panter, D. Rindskopf and K. J. Sher (eds.), APA Handbook of Research Methods in Psychology, Vol. 2. Research Designs: Quantitative, Qualitative, Neuropsychological, and Biological, 57-71. Washington, DC: American Psychological Association.

Conner, Norma E. and Susan K. Chase (2015): Decisions and Caregiving: End of Life Among Blacks from the Perspective of Informal Caregivers and Decision Makers. The American Journal of Hospice and Palliative Care 32 (4): 454-463.

Cook, Erica J., Gurch Randhawa, Andy Guppy, Chloe Sharp, Garry Barton, Andrew Bateman and Jane Crawford-White (2017): Exploring Factors That Impact the Decision To Use Assistive Telecare: Perspectives of Family Care-Givers of Older People in the United Kingdom. Ageing and Society 38 (9): 1912-1932.

Dolničar, Vesna, Andraž Petrovčič, Mojca Šetinc, Igor Košir and Matic Kavčič (2017): Understanding Acceptance Factors for Using E-Care Systems and Devices: Insights From a Mixed-Method Intervention Study in Slovenia. In Jia and Gavriel Salvendy (eds.), Human Aspects of IT for the Aged Population: Applications, Services and Contexts: Third International Conference, ITAP 2017 proceedings 2 10298: 362-377. New York: Springer International Publishing. 
Epstein, Iris, Allan Aligato, Tyler Krimmel and Alex Mihailidis (2016): Older Adults' and Caregivers' Perspectives on In-Home Monitoring Technology. Journal of Gerontological Nursing 42 (6): 43-50.

Gibson, Grant, Claire Dickinson, Katie Brittain and Louise Robinson (2019): Personalisation, Customisation and Bricolage: How People with Dementia and Their Families Make Assistive Technology Work for Them. Ageing and Society 39 (11): 2502-2519.

Golant, Stephen M. (2017): A Theoretical Model to Explain the Smart Technology Adoption Behaviors of Elder Consumers (Elderadopt). Journal of Aging Studies 42: $56-73$.

Guisado-Fernández, Estefanía, Guido Giunti, Laura M. Mackey, Catherine Blake and Brian Michael Caulfield (2019): Factors Influencing the Adoption of Smart Health Technologies for People with Dementia and Their Informal Caregivers: Scoping Review and Design Framework. JMIR Aging 2 (1): e12192.

Harward, Nat (2016): Caregivers and Technology: What They Want and Need. A guide for innovators - Research from a nationally representative sample of America's 40 million family caregivers. Accessible at http://www.aarp.org/content/dam/aarp/home-and-family/personal-technology/2016/04/Caregiversand-Technology-AARP.pdf, 14. 1. 2020.

Hassan, Alhassan Yosri Ibrahim (2020): Challenges and Recommendations for the Deployment of Information and Communication Technology Solutions for Informal Caregivers: Scoping Review. JMIR Aging 3 (2): e20310.

Huber, Lesa Lorenzen, Kalpana Shankar, Kelly Caine, Kay Connelly, L. Jean Camp, Beth Ann Walker and Lisa Borrero (2013): How In-Home Technologies Mediate Caregiving Relationships in Later Life. International Journal of HumanComputer Interaction 29 (7): 441-455.

Hvalič Touzery, Simona, Kaja Smole-Orehek and Vesna Dolničar (2021): Family Carers' Perspective n How Older People Perceive Telecare. Places, Spaces and Cultures of Ageing - European Sociological Association's Research Network on Ageing in Europe Midterm conference. Jyväskylä: University of Jyväskylä.

Jaschinski, Christina, Somaya Ben Allouch, Oscar Peters, Ricardo Cachucho and Jan A. G. M. van Dijk (2021): Acceptance of Technologies for Aging in Place: A Conceptual Model. Journal of Medical Internet Research 23 (3): e22613.

Jaschinski, Christina and Somaya Ben Allouch (2019): Listening to the Ones Who Care: Exploring the Perceptions of Informal Caregivers Towards Ambient Assisted Living Applications. Journal of Ambient Intelligence and Humanized Computing 10 (2): 761-778.

Kröger, Teppo, Jiby Mathew Puthenparambil and Lina Van Aerschot (2019): Care Poverty: Unmet Care Needs in a Nordic Welfare State. International Journal of Care and Caring 3 (4): 485-500.

Liu, Lili, Eleni Stroulia, Ioanis Nikolaidis, Antonio Miguel-Cruz and Adriana Rios Rincon (2016): Smart Homes and Home Health Monitoring Technologies for Older Adults: A Systematic Review. International Journal of Medical Informatics 91: 44-59. 
Lobo, Michele A., Sarah H. Kagan and John D. Corrigan (2017): Research Design Options for Intervention Studies. Pediatric Physical Therapy: The Official Publication of the Section on Pediatrics of the American Physical Therapy Association, 29 (Suppl 3): S57-S63.

Luijkx, Katrien, Sebastiaan Peek and Eveline Wouters (2015): "Grandma, You Should Do It -It's Cool" Older Adults and the Role of Family Members in Their Acceptance of Technology. International Journal of Environmental Research and Public Health 12 (12): 15470-15485.

Mitchell, Lauren L., Colleen M. Peterson, Shaina R. Rud, Eric Jutkowitz, Andrielle Sarkinen, Sierra Trost, Carolyn M. Porta, Jessica M. Finlay and Joseph E. Gaugler (2020): "It's Like a Cyber-Security Blanket": The Utility of Remote Activity Monitoring in Family Dementia Care. Journal of Applied Gerontology: The Official Journal of the Southern Gerontological Society 39 (1): 86-98.

Namey, Emily E., Greg Guest, Lucy Thairu and Laura Johnson (2008): Data Reduction Techniques for Large Qualitative Data Sets. In G. Guest and K. M. MacQueen (eds.), Handbook for Team-Based Qualitative Research, 137-161. Lanham: AltaMira Press.

Normie, Lawrence (2011): Technology for Ageing in Place. IFA Global Ageing 7 (2): 45-53.

Peek, Sebastiaan (2017): Understanding technology acceptance by older adults who are aging in place: A dynamic perspective. PhD Thesis. Enschede: Tilburg University. Accessible at https://pure.uvt.nl/ws/files/18477610/PhD_Thesis_ Sebastiaan_Peek.pdf, 21.9. 2018.

Šadl, Zdenka and Valentina Hlebec (2018): Družinska oskrba ostarelih staršev in spolne razlike v Sloveniji. Teorija in Praksa 55 (4): 732-761.

Saldaña, Johnny (2011): Fundamentals of Qualitative Research: Understanding Qualitative Research (First edition). Oxford: Oxford University Press

Saldaña, Johnny (2013): The Coding Manual for Qualitative Researchers (Second edition). London: SAGE Publications.

Smole-Orehek, Kaja, Simona Hvalič-Touzery, Andraž Petrovčič, Vesna Dolničar, Matjaž Debevc and Ines Kožuh (2019): Psychological Outcomes of eCare Technologies Use for Informal Carers: A Scoping Study. Gerontechnology 18: $15-28$.

Sriram, Vimal, Crispin Jenkinson and Michele Peters (2019): Informal Carers' Experience of Assistive Technology Use in Dementia Care at Home: A Systematic Review. BMC Geriatrics 19 (1): 160.

Steils, Nicole, John Woolham, Malcolm Fisk, Jeremy Porteus and Kirsty Forsyth (2021): Carers' Involvement in Telecare Provision by Local Councils for Older People in England: Perspectives of Council Telecare Managers and Stakeholders. Ageing and Society 41 (2): 456-475.

Thiese, Matthew S. (2014): Observational and Interventional Study Design Types: An Overview. Biochemia Medica 24 (2): 199-210.

Topo, Päivi (2009): Technology Studies to Meet the Needs of People with Dementia and Their Caregivers: A Literature Review. Journal of Applied Gerontology 28 (1): 5-37. 
Tsertsidis, Antonios, Ella Kolkowska and Karin Hedström (2019): Factors Influencing Seniors' Acceptance of Technology for Ageing in Place in the PostImplementation Stage: A Literature Review. International Journal of Medical Informatics 129: 324-333.

Verloo, Henk, Thomas Kampel, Nicole Vidal and Filipa Pereira (2020): Perceptions about Technologies That Help Community-Dwelling Older Adults Remain at Home: Qualitative Study. Journal of Medical Internet Research 22 (6).

Williamson, Brittany, Tammy Aplin, Desleigh de Jonge and Matthew Goyne (2017): Tracking Down a Solution: Exploring the Acceptability and Value of Wearable GPS Devices for Older Persons, Individuals with a Disability and Their Support Persons. Disability and Rehabilitation. Assistive Technology 12 (8): 822-831.

\section{SOURCES}

Eurocarers (2018): Enabling carers to care. An EU Strategy to support and empower informal carers. Brussels: Eurocarers: European Association Working for Carers Eurocarers, 2018. Accessible at https://eurocarers.org/publications/enablingcarers-to-care/, 4. 6. 2021.

Eurocarers (2019): Information and Communication Technology (ICT) for informal carers - Position Paper. Eurocarers: European Association Working for Carers Eurocarers, 2019. Accessible at https://eurocarers.org/publications/ information-communication-technology-ict-for-informal-carers/Fiche_ICT-2020 _web.pdf, 8. 1. 2021.

European Ageing Network (2019): Long-Term Care 2030. Luxembourg: European Ageing Network, 2019. Accessible at https://www.ean.care/media/fileman/LTC _2030_ebook_2nd_edition_v2.pdf, 17.2.2021.

Spasova, Slavina, Rita Baeten, Stéphanie Coster, Dalila Ghailani, Ramón Peña-Casas and Bart Vanhercke (2018): Challenges in long-term care in Europe - A study of national policies (KE-01-18-637-EN-N). Brussels: European Commission, Directorate-General for Employment, Accessible at Social Affairs and Inclusion. https://ec.europa.eu/social/BlobServlet?docId=20225andlangId=en, 3. 2. 2021.

World Health Organization (2012): Strategy and action plan for healthy ageing in Europe, 2012-2020. World Health Organization Regional Office for Europe, 2012. Accessible at http://www.euro.who.int/_data/assets/pdf_file/ 0008/175 544/RC62wd10Rev1-Eng.pdf?ua=1, 8. 1. 2021. 